\title{
Very Early Neonatal Death
}

National Cancer Institute

\section{Source}

National Cancer Institute. Very Early Neonatal Death. NCI Thesaurus. Code C120592.

Death of a live newborn during the first 24 hours of life 